\title{
Approaching Sub-ppm Level Asymmetric Organocatalysis of a Highly Challenging and Scalable Carbon-Carbon Bond Forming Reaction
}

\author{
Han Yong Bae, ${ }^{a}$ Denis Höfler, ${ }^{a}$ Philip S. J. Kaib, ${ }^{a}$ Pinar Kasaplar, ${ }^{a}$ Chandra Kanta De, ${ }^{a}$ Arno Döhring, ${ }^{a}$ Sunggi Lee, ${ }^{a}$ Karl \\ Kaupmees, ${ }^{\text {b }}$ Ivo Leito ${ }^{\mathrm{b}}$ and Benjamin List ${ }^{\mathrm{a} *}$
}

\author{
${ }^{\text {a} M a x-P l a n c k-I n s t i t u t ~ f u ̈ r ~ K o h l e n f o r s c h u n g, ~ K a i s e r-W i l h e l m-P l a t z ~ 1, ~ D-45470 ~ M u ̈ l h e i m ~ a n ~ d e r ~ R u h r, ~ G e r m a n y . ~}$

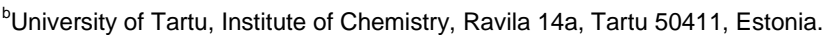 \\ *email: list@kofo.mpg.de
}

\begin{abstract}
The chemical synthesis of organic molecules involves, at its very essence, the creation of carbon-carbon bonds. In this context, the aldol reaction is among the most important synthetic methods, and a wide variety of catalytic and stereoselective versions have been reported. However, aldolizations yielding tertiary aldols, which result from the reaction of an enolate with a ketone, are challenging and only a few catalytic asymmetric Mukaiyama aldol reactions with ketones as electrophiles have been described. These methods typically require relatively high catalyst loadings, deliver substandard enantioselectivity or need special reagents or additives. We now report extremely potent catalysts that readily enable the reaction of silyl ketene acetals with a diverse set of ketones to furnish the corresponding tertiary aldol products in excellent yields and enantioselectivities. Parts per million (ppm) levels of catalyst loadings can be routinely used and provide fast and quantitative product formation in high enantiopurity. In situ spectroscopic studies and acidity measurements suggest a silylium ion based, asymmetric counteranion-directed Lewis acid catalysis mechanism.
\end{abstract}

Chiral tertiary aldols are encountered in a variety of natural products and pharmaceuticals (Fig. 1a). ${ }^{1}$ Despite the considerable advances in catalytic asymmetric aldol reactions of aldehydes, ${ }^{2-6}$ only a few examples using ketones as electrophiles are known to date $^{7-9}$ Thermodynamics typically favor the corresponding retro-aldol reaction, ${ }^{10-13}$ while the lower reactivity of ketones, compared to aldehydes, further challenge the reaction kinetically. Importantly though, the energy that is released in the tautomerization of the initial enol product of the reverse aldol reaction to the ketone is absent in the corresponding Mukaiyama variant. Therefore, the forward Mukaiyama aldol reaction ${ }^{14-16}$ is favored, even with ketones. However, the enantiofacial differentiation of ketones is still much more challenging than that of aldehydes. ${ }^{17}$ The Denmark group disclosed the first Mukaiyama aldol reaction of ketones catalyzed by chiral bis- $\mathrm{N}$-oxides acting as Lewis base. ${ }^{17,18}$ This method requires the use of highly reactive trichlorosilyl enolates of methyl acetate as the nucleophile (Fig. 1b, top scheme). Shibasaki and Kanai developed an enantioselective Mukaiyama aldol reaction of trimethylsilyl enolates to ketones in the presence of a chiral copper(I) fluoride-phosphine complex as the catalyst (Fig. 1b, bottom scheme). ${ }^{19}$ Furthermore, the group of Campagne reported that chiral 2,2'-bis(di-p-tolylphosphino)-1,1'-binaphthyl (Tol-BINAP)-copper (II) trifluoromethanesulfonate catalyzes vinylogous Mukaiyama aldol reaction of ketones. ${ }^{20}$ Despite these advances, a more practical and general protocol for the Mukaiyama aldol reaction of ketones was envisioned exploiting the extraordinary reactivity of our recently developed imidodiphosphorimidate (IDPi) catalysts. ${ }^{21-25}$ In recent years, our group has made progress in the field of silylium based, asymmetric counteranion-directed Lewis acid catalysis (silylium ACDC) ${ }^{26}$ of Mukaiyama-type ${ }^{27-29}$ reactions. These transformations invariably require the use of aldehydes or imines as electrophiles, while ketones have remained elusive. 


\section{Results and discussion}

\section{Optimization of catalyst and silyl ketene acetal.}

For our initial studies, the addition of silyl ketene acetal $\mathbf{2 a}$ to 2-acetonaphthone (1a) was chosen as a model reaction (Fig. 2). Indeed, with $0.1 \mathrm{~mol} \%$ of chiral disulfonimide (DSI) catalyst $\mathbf{C}-1,{ }^{27,30,31}$ no desired product was detected even after prolonged reaction times (24 h). Full consumption of the ketone was observed but instead of the desired aldol product, only silyl enol ether $\mathbf{4}$ was obtained. In sharp contrast, with 0.1 mol\% of IDPi catalyst C-2, the tertiary aldol product 3aa was formed within three minutes and with an enantiomeric ratio (e.r.) of 69.5:30.5.

With these exciting results in hand, an increase in enantioselectivity through further synthetic manipulations of the four aryl substitutents at the 3,3'-positions of the chiral 1,1'-bi-2-naphthol (BINOL) scaffold of the catalyst, was pursued (Table 1, for detailed results on the optimization of solvents and silyl ketene acetals, see Supplementary Table 1). Besides the reported catalysts $\mathbf{C}-2$ and $\mathbf{C}-\mathbf{3},{ }^{21}$ several new IDPi catalysts were synthesized (C-4, C-5, C-6, C-7 and C-8) and applied to the model reaction. Gratifyingly, elongating the alkyl chains at the 3,5-positions of the four aryl substituents increased the enantioselectivity, ultimately leading to an e.r. of $97: 3$ with catalyst C-8 (entries 4 to 7 ).

In all cases, the catalytic activities were extremely high and the reaction was completed within 30 minutes with 1.0 mol\% of catalyst. Moreover, the catalyst loading can be reduced to $0.05 \mathrm{~mol} \%$ (= $500 \mathrm{ppm})$ without deterioration of yield and enantioselectivity ( $97: 3$ e.r., entry 8). After screening of several different silyl ketene acetals (2a-2d), tert-butyldimethylsilyl (TBS) or triethylsilyl (TES) proved to be the most suitable silyl groups in terms of reactivity and enantioselectivity (entries 8 to 11).

\section{Ketone scope and synthetic utility.}

Under the optimized reaction conditions, a variety of ketones (1)-1v) were subjected to this protocol (Table 2). Remarkably, a loading of 0.005 to 0.05 mol\% (50 to 500 ppm) with catalysts $\mathbf{C}-4, \mathbf{C}-\mathbf{7}$ or $\mathbf{C}-\mathbf{8}$ in $\mathrm{Et}_{2} \mathrm{O}$ at $-20^{\circ} \mathrm{C}$ proved to be sufficient to provide the desired products $(\mathbf{3 b} \mathbf{b} \mathbf{3 v})$ in quantitative yields (up to $>99 \%$ ) and with excellent e.r. (up to >99:1). Besides (hetero)aryl-alkyl ketones (1b-1k), alkyl-alkyl ketones (1m-10) were also converted with good to excellent e.r. (88:12 to 95:5). Alkynyl ketone 1p gave an excellent e.r. of 95:5. Interestingly, benzylideneacetone-type $\alpha, \beta$-unsaturated ketones $\mathbf{1 q}-\mathbf{1} \mathbf{v}$ were highly reactive and generally gave good 1,2- vs. $1,4-$ regioselectivity (5:1-10:1) and excellent enantioselectivity (e.r. = 97.5:2.5 to >99:1). Ketones other than methyl ketones, ethyl ketone 1c and cyclic ketone $1 \mathrm{I}$ were also successfully transformed into the desired products 3c and 3 I (e.r. = 94:6 and 86:14), respectively.

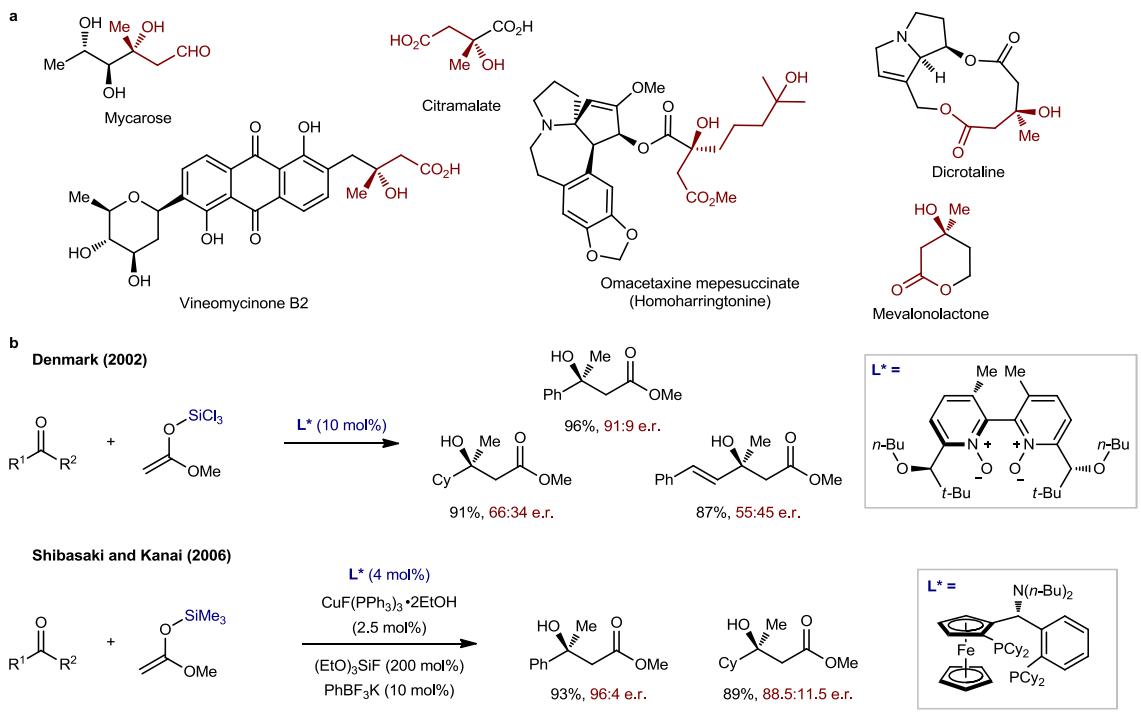

Figure 1 | Representative examples of tertiary aldol containing natural products and catalytic asymmetrtic routes to these moieties. a, Natural products containing tertiary aldols. b. Previously reported asymmetric Mukaiyama aldol reactions of ketones as electrophiles, using trichlorosilyl enolates of methyl acetate catalyzed by chiral Lewis base (top scheme) and trimethylsilyl enolates catalyzed by chiral copper(I) fluoride-phosphine complex (bottom scheme). Cy $=$ cyclohexyl, $\mathrm{L}^{*}=\mathrm{chiral}$ ligand. 


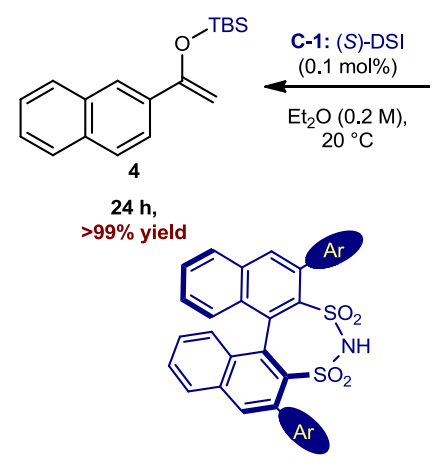

C-1: (S)-DSI
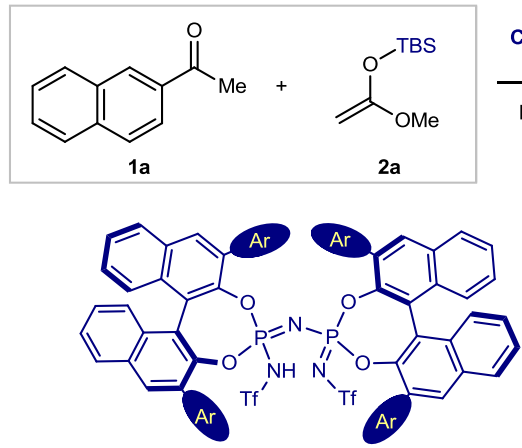

C-2: $(S, S)-I D P i$

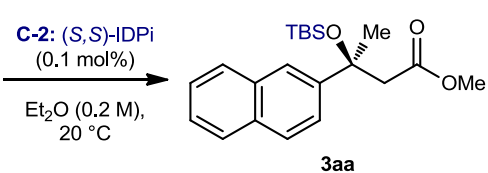

3aa

$<3 \mathrm{~min}$,

$>99 \%$ yield<smiles>FC(F)(F)c1cc(C(F)(F)F)cc(C(F)(F)F)c1</smiles>

Figure 2 | Reactivity comparison of DSI C-1 and IDPi C-2 in the Mukaiyama aldol reaction of ketone as electrophile under the identical reaction conditions. Reactions were performed with ketone $1 \mathbf{a}(0.5 \mathrm{mmol})$, silyl ketene acetal $\mathbf{2 a}\left(2.0\right.$ equiv.), and catalyst $(\mathbf{C}-1$ or $\mathbf{C}-2,0.1 \mathrm{~mol} \%)$ in $\mathrm{Et}_{2} \mathrm{O}(2.5 \mathrm{~mL}, 0.2 \mathrm{M})$ at $20{ }^{\circ} \mathrm{C}$. The yield was determined after chromatographic purification and the enantiomeric ratio (e.r.) was determined by high performance liquid chromatography $(\mathrm{HPLC})$ analysis. $\mathrm{Tf}^{=} \mathrm{SO}_{2} \mathrm{CF}_{3}$, $\mathrm{TBS}=\mathrm{SiMe}_{2} t-\mathrm{Bu}$.

To illustrate the synthetic utility of our method, derivatizations of the chiral tertiary aldols 3 were performed. Due to the high volatility of silyl ketene acetal $\mathbf{2}$ and the extremely low catalyst loading, analytically pure product $\mathbf{3}$ could be easily obtained after removing the volatiles under reduced pressure. The clean reaction profile of products allowed the direct conversion of the material without the need for further chromatographic purification. Several functionalized chiral tertiary alcohols such as $\beta$-silyloxy aldehyde 5 (89\%, 95:5 e.r.) diols 6 (two steps, 92\%, 95:5 e.r.) and 7 (88\%, 95:5 e.r.), carboxylic acid 8 (91\%, 95:5 e.r.), a product of transesterification (9, 84\%, 95:5 e.r.), and amide 10 (two steps, 83\%, 95:5 e.r.) were successfully obtained. In addition, chiral tertiary aldols $\mathbf{3 p}$ and $\mathbf{3 u}$ were quantitatively transformed to product $\mathbf{3 n}$, without erosion of e.r. (see Supplementary Sections 7 and 8 for details).

Table 1 | Optimization of the IDPi catalysts and the silyl ketene acetals 2.<smiles>CC(=O)c1ccc2ccccc2c1</smiles>

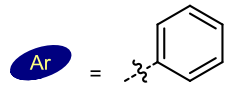
C-3<smiles>C=C(OC)O[Ga]O</smiles>

2a-2d

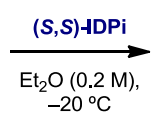
$-20^{\circ} \mathrm{C}$<smiles>c1ccc2ccccc2c1</smiles>
C-4<smiles>[R9]O[C@@](C)(CC(=O)OC)c1ccc2ccccc2c1</smiles>
3aa-3ad<smiles>Cc1cc(I)cc([N+](=O)[O-])c1</smiles>

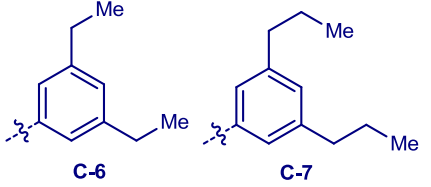<smiles>CCCCCCc1cc(C)cc(CCCCCC)c1</smiles>

\begin{tabular}{|c|c|c|c|c|c|}
\hline Entry & Catalyst (mol\%) & $\mathrm{SiR}_{3}$ & Time (h) & Yield (\%) & e.r. \\
\hline 1 & C-2 (1.0) & TBS $\left(\mathrm{SiMe}_{2} t-\mathrm{Bu}, \mathbf{2 a}\right)$ & $<0.5$ & 99 (3aa) & $75: 25$ \\
\hline 2 & C-3 (1.0) & TBS $(\mathbf{2 a})$ & $<0.5$ & 99 (3aa) & $79.5: 21.5$ \\
\hline 3 & C-4 (1.0) & TBS (2a) & $<0.5$ & 99 (3aa) & $89: 11$ \\
\hline 4 & C-5 (1.0) & TBS (2a) & $<0.5$ & 99 (3aa) & $91: 9$ \\
\hline 5 & C-6 (1.0) & TBS $(\mathbf{2 a})$ & $<0.5$ & 99 (3aa) & $95.5: 4.5$ \\
\hline 6 & C-7 (1.0) & TBS $(\mathbf{2 a})$ & $<0.5$ & 99 (3aa) & $95.5: 4.5$ \\
\hline 7 & C-8 $(1.0)$ & TBS $(\mathbf{2 a})$ & $<0.5$ & 99 (3aa) & $97: 3$ \\
\hline 8 & $\mathrm{C}-8(0.05=500 \mathrm{ppm})$ & TBS $(\mathbf{2 a})$ & 12 & 99 (3aa) & $97: 3$ \\
\hline 9 & C-8 $(0.05=500 \mathrm{ppm})$ & TMS $\left(\mathrm{SiMe}_{3}, \mathbf{2 b}\right)$ & 12 & 99 (3ab) & $89: 11$ \\
\hline 10 & $\mathbf{C}-\mathbf{8}(0.05=500 \mathrm{ppm})$ & $\mathrm{TES}\left(\mathrm{SiEt}_{3}, \mathbf{2} \mathbf{c}\right)$ & 12 & 99 (3ac) & $95.5: 4.5$ \\
\hline $11^{\mathrm{a}}$ & C-8 $(0.05=500$ ppm $)$ & 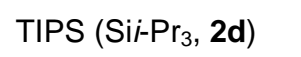 & 24 & 67 (3ad) & $69: 31$ \\
\hline
\end{tabular}

Reactions were performed with ketone $1 \mathrm{a}(0.5 \mathrm{mmol})$, silyl ketene acetal $2\left(2.0\right.$ equiv.), and catalyst $(0.05$ to $1.0 \mathrm{~mol} \%)$ in $\mathrm{Et}_{2} \mathrm{O}(2.5 \mathrm{~mL}, 0.20 \mathrm{M})$ at $-20^{\circ} \mathrm{C}$. All yields are those of isolated products and the enantiomeric ratio (e.r.) was determined by HPLC analysis. ${ }^{a}$ Reaction was performed at $24{ }^{\circ} \mathrm{C}$. 
Toward extremely low catalyst loadings.

To further investigate the performance of the IDPi catalyst $\mathbf{C - 8}$, very low catalyst loadings ${ }^{32}$ experiments were implemented on a preparative scale. Deca-grams of products $3 \mathbf{i}(>99 \%, 20.5 \mathrm{~g})$ and $\mathbf{3 v}(92 \%, 20.1 \mathrm{~g})$ were quantitatively obtained in very high enantioselectivities (95:5 e.r. and 96:4 e.r.) using 25 ppm or 2.8 ppm of the catalysts, respectively (Fig. 3a, see Supplementary Section 12 for analytical results). Substrate $1 \mathbf{u}$ was further explored. ${ }^{17}$ Due to the existence of a background reaction (see Supplementary Fig. 2), conditions suitable for obtaining excellent e.r. in these large scale syntheses were first identified (at $5{ }^{\circ} \mathrm{C}$ with $8.0 \mathrm{M}$ conc., see Supplementary Table 3 for full data). Initially, we fixed the amount of ketone $1 \mathbf{u}$ at $1.00 \mathrm{~g}$ and lowered the catalyst loadings from 8 ppm $(0.10 \mathrm{mg})$ to $2.8 \mathrm{ppm}(0.037 \mathrm{mg})$. In all cases, full conversion of $1 \mathbf{u}$ and quantative yield of tertiary aldol product $3 \mathbf{u}(\sim 90 \%$ yield) with $>95: 5$ e.r. was observed. Excitingly, with $30.0 \mathrm{~g}$ of substrate, only $1.1 \mathrm{mg}$ of IDPi C-8 successfully produced $59.2 \mathrm{~g}$ of the enantioenriched product ( $86 \%$ corrected yield, TON 307000 , Fig. 3a, see Supplementary Table 4). Ketone 1u was partially soluble at the early stage of the reaction, and slowly dissolved during the course of the reaction, finally leading to a homogeneous solution (Fig. 3d).

We also investigated the repeated addition of starting materials after consumption of the initial reaction mixture with 2.8 ppm catalyst loading (batch A, Fig. 3b, see Supplementary Table 5). Upon completion of the reaction and removal of the volatiles, starting materials and solvent were recharged and subjected to the aldol reaction under the same conditions without the addition of more catalyst (batch B, see Supplementary Table 6). A third portion of substrate and reagent was added (batch C, see Supplementary Table 7), ultimately leading to a total conversion of $95.2 \%$ (82\% yield: total TON 911000$)$. It is noteworthy that ppm-level loadings in organocatalysis have previously been reported, for instance, in silylative kinetic resolutions of racemic alcohols ${ }^{33}$ and in asymmetric transfer hydrogenations. ${ }^{34}$ To the best of our knowledge, however, approaching sub-ppm level loadings ( $<1 \mathrm{ppm}$, Fig. $3 \mathrm{~b}$ and $\left.3 \mathrm{c}\right)$ of an organocatalyst in a challenging carbon-carbon bond forming reaction with high enantioselectivity is unprecedented .

In contrast to the formidable catalytic activity of our IDPi catalyst, DSI C-1 $(0.1 \mathrm{~mol} \%)$ provided a mixture of 1,4 -addition product 11 with tertiary aldol $3 \mathbf{u}$ (47:53 e.r., $54 \%$ isolated yield, $\mathbf{1 1 / 3 u}=1.5: 1$, see Supplementary Fig. 5 ). In addition, the silyl enol ether of starting ketone 1u (compound 12, 4\%) was also generated (Fig. 3e).

\section{Investigation of the reaction mechanism.}

To gain insights into the reaction mechanism, real time analytical investigations were conducted using in situ FT-IR (Fourier transform infrared) spectroscopy (Fig. 4a). ${ }^{35,36}$ The absorption peak of the carbonyl group of ketone 1a at $1688 \mathrm{~cm}^{-1}$ was monitored during the reaction in the presence of $0.1 \mathrm{~mol} \%$ of IDPi catalyst $\mathbf{C}-6$ at $20^{\circ} \mathrm{C}$ (step A). After 7 min, silyl ketene acetal $2 \mathbf{a}\left(1656 \mathrm{~cm}^{-1}\right)$ was added to the reaction mixture (step B). The reaction proceeded rapidly and was completed in less than three minutes (>99\% conversion by ${ }^{1} \mathrm{H}$ NMR spectroscopy) to give aldol 3aa (left picture, $1744 \mathrm{~cm}^{-1}$ ) as a single product with an e.r. of 95:5. As previously mentioned, DSI C-1 did not catalyze the desired transformation but exclusively gave silyl enol ether 4 instead (right picture, $1751 \mathrm{~cm}^{-1}$ ). ${ }^{37} \mathrm{The} \mathrm{remarkably}^{-1}$ different reaction outcomes may be explained by considering counteranion basicities. We measured $p K_{a}$ values of several different chiral Brønsted acid catalysts, which were developed in our research group, with reference to some achiral acids in acetonitrile (Fig. 4b, see Supplementary Table 10 for $p K_{a}$ values of our chiral acid organocatalysts and the corresponding references). In line with our previous investigations, ${ }^{21,23,25}$ we propose that our IDPi catalyst is a precatalyst, which is silylated by ketene acetal $2 \mathbf{2 a}$ to give the equivalent of a silylium ion pair $\mathbf{1 3}$ as the catalytically relevant Lewis acid (Fig. 4c). Silylium transfer onto the ketone then furnishes an oxocarbenium ion pair, the fate of which is dependent on the counteranion, i.e. the DSI anion is sufficiently basic to deprotonate the oxocarbenium ion and furnishes the corresponding enol silane ( $\mathrm{p} K_{\mathrm{a}}$ of DSI C-1 = 8.4). In contrast, the IDPi anion is only a very weak base, enabling the desired Mukaiyama pathway to occur ( $\mathrm{p} K_{\mathrm{a}}$ of IDPi $\mathbf{C}-3=4.5$, in acetonitrile). 


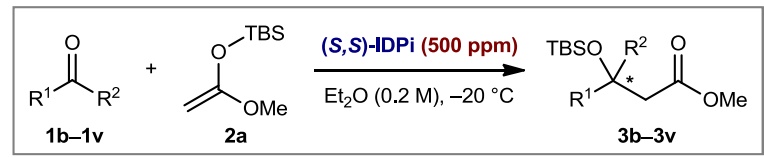
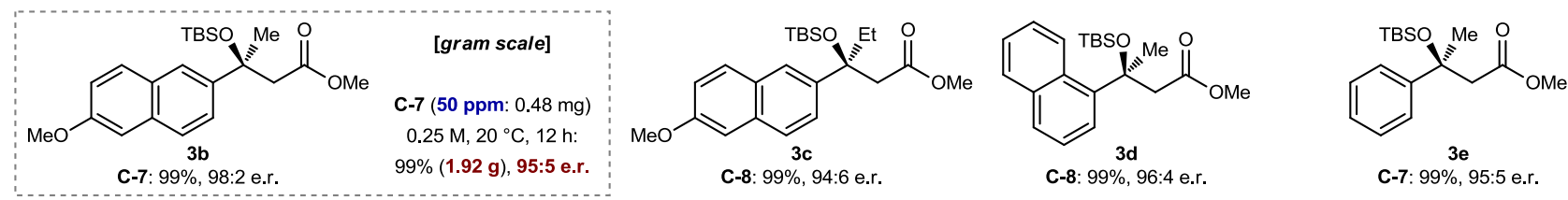

3e
C-7: $99 \%, 95: 5$ e.r.<smiles>COC(=O)C[C@@](C)(O)c1ccc(OC)c(OC)c1</smiles>

$3 \mathrm{~h}$

C-8: $99 \%, 97: 3$ e.r. C-8: $99 \%, 92: 8$ e.r.

C-8: $96 \%, 92: 8$ e.r [gram scale]<smiles>COC(=O)CC(C)(O)c1cccs1</smiles>

$3 \mathbf{k}$ C-8 (100 ppm: $1.5 \mathrm{mg}$ ) $2.0 \mathrm{M}, 0^{\circ} \mathrm{C}, 3 \mathrm{~d}$ : $99 \%(2.47 \mathrm{~g}), 95: 5$ e.r. C-8 8 (50 ppm: $0.76 \mathrm{mg})$ $2.0 \mathrm{M}, 0{ }^{\circ} \mathrm{C}, 7 \mathrm{~d}$ :

C-8: $99 \%, 97: 3$ e.r. $90 \%(2.25 \mathrm{~g}), 95: 5$ e.r.<smiles>COC(=O)C[C@@](C)(O)c1ccc(OC)cc1</smiles><smiles>COC(=O)CC1(O[Na])CC[CH]c2ccccc21</smiles>
C-8: 93\%, 86:14 e.r.<smiles>COC(=O)C[C@@](C)(O[13C]([14CH3])[14CH3])C1CCCCC1</smiles>

C-7: $99 \%, 95: 5$ e.r<smiles></smiles><smiles>COC(=O)C[C@](C)([18OH])CCc1ccccc1</smiles>

$3 n$

C-4: $94 \%, 88: 12$ e.r.

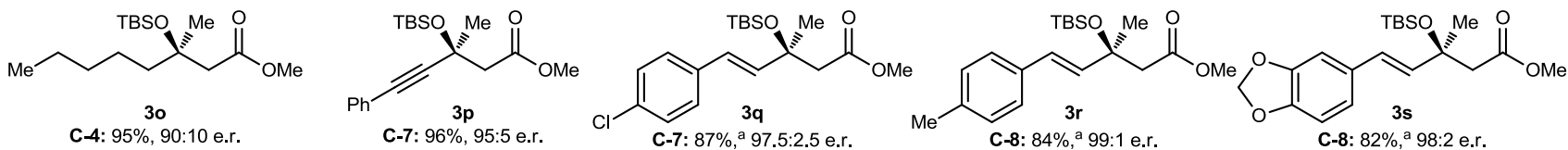

C-4: $95 \%, 90: 10$ e.r. C-7: $96 \%, 95: 5$ e.r.

C-7: $87 \%,{ }^{a} 97.5: 2.5$ e.r.<smiles>COC(=O)C[C@@]([14CH3])(O)/C=C/c1ccco1</smiles>

C-8: $78 \%$, ${ }^{\text {a }} 99: 1$ e.r.<smiles>COc1ccc([C@](C)(CC(C)(C)O)c2ccc(OC)c(OC)c2)cc1</smiles>

$80 \%, 95: 5$ e.r.<smiles>COC(=O)C[C@@](C)(O)/C=C/c1ccccc1</smiles>
C-8: $91 \%$, a $97.5: 2.5$ e.r.
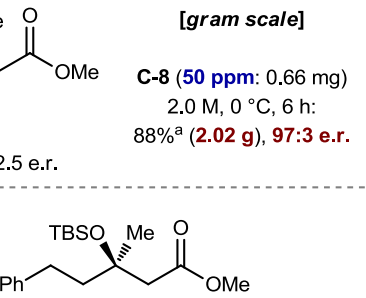

3n, quant. 95:5 e.r. and 97.5:2.5 e.r.
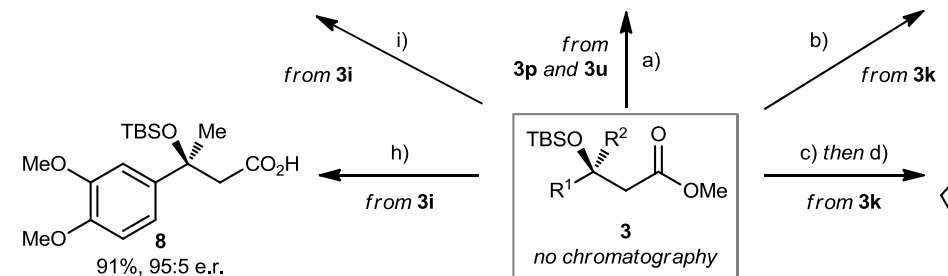
from 3ab, 3ad, 3e, 3k and 3u $\begin{aligned} & \text { d) } \\ & \text { from 3m }\end{aligned}$

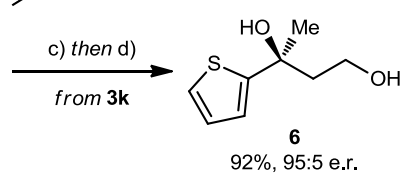

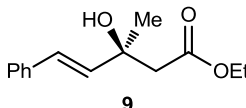

$84 \%, 95: 5$ e.r.
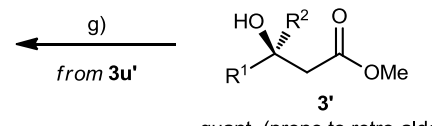

quant. (prone to retro-aldol)

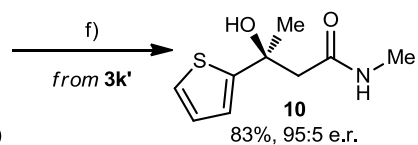

Conditions:

a) $\mathrm{Et}_{3} \mathrm{Si}-\mathrm{H}$ (10 equiv.), $\mathrm{Pd} / \mathrm{C}$ (10 wt\%), $\mathrm{MeOH}, 20^{\circ} \mathrm{C}, 1 \mathrm{~h}$

b) DIBAL-H (1.1 equiv.), $\mathrm{CH}_{2} \mathrm{Cl}_{2}$, $-78^{\circ} \mathrm{C}, 1.5 \mathrm{~h}$

c) $\mathrm{LiAlH}_{4}$ (1.2 equiv.), THF, $0{ }^{\circ} \mathrm{C}, 6 \mathrm{~h}$ d) $n-\mathrm{Bu}_{4} \mathrm{NF}$ (2.0 equiv.), THF, $0^{\circ} \mathrm{C}, 3 \mathrm{~h}$ e) $\mathrm{CH}_{2} \mathrm{Cl}_{2} / \mathrm{CF}_{3} \mathrm{CO}_{2} \mathrm{H}(50: 1, \mathrm{v} / \mathrm{v})$, $0{ }^{\circ} \mathrm{C}$ to r.t., $12 \mathrm{~h}$

f) $\mathrm{NH}_{2} \mathrm{Me}\left(5.0\right.$ equiv.), $\mathrm{THF}, 70^{\circ} \mathrm{C}, 12 \mathrm{~h}$

g) $\mathrm{Zn}_{4}\left(\mathrm{OCOCF}_{3}\right)_{6} \mathrm{O}(10 \mathrm{wt} \%)$ $\mathrm{EtOH}, 75^{\circ} \mathrm{C}, 12 \mathrm{~h}$

h) $\mathrm{LiOH}$ (5.0 equiv.), water (10 equiv.),

$\mathrm{MeOH} / \mathrm{THF}(\mathrm{v} / \mathrm{v} 1: 1), 65^{\circ} \mathrm{C}, 3 \mathrm{~h}$

then $\mathrm{HCl}(10 \%$ aq.), $\mathrm{pH}=7$

i) $\mathrm{MeMgl}$ (2.2 equiv.), $\mathrm{CH}_{2} \mathrm{Cl}_{2}$,

$0{ }^{\circ} \mathrm{C}, 24 \mathrm{~h}$

Reactions were performed with ketone $1(0.5 \mathrm{mmol})$, silyl ketene acetal $2 \mathrm{a}\left(2.0\right.$ equiv.) and IDPi catalyst $(0.05 \mathrm{~mol} \%=500 \mathrm{ppm})$ in $\mathrm{Et}_{2} \mathrm{O}(2.5 \mathrm{~mL}, 0.20 \mathrm{M})$ at $-20{ }^{\circ} \mathrm{C}$ for $12-72$ h. Gram scale reactions were performed with ketone 1 ( $1.0 \mathrm{~g}$ ), silyl ketene acetal $\mathbf{2 a}$ (1.1 equiv.) and IDPi catalyst (50 or $100 \mathrm{ppm}$ ) in $\mathrm{Et}_{2} \mathrm{O}$ under the indicated conditions. All

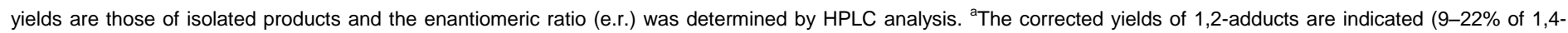
adducts were observed, see Supplementary Section 11 for details). ${ }^{\text {b }}$ No 1,4 -adduct was observed. 


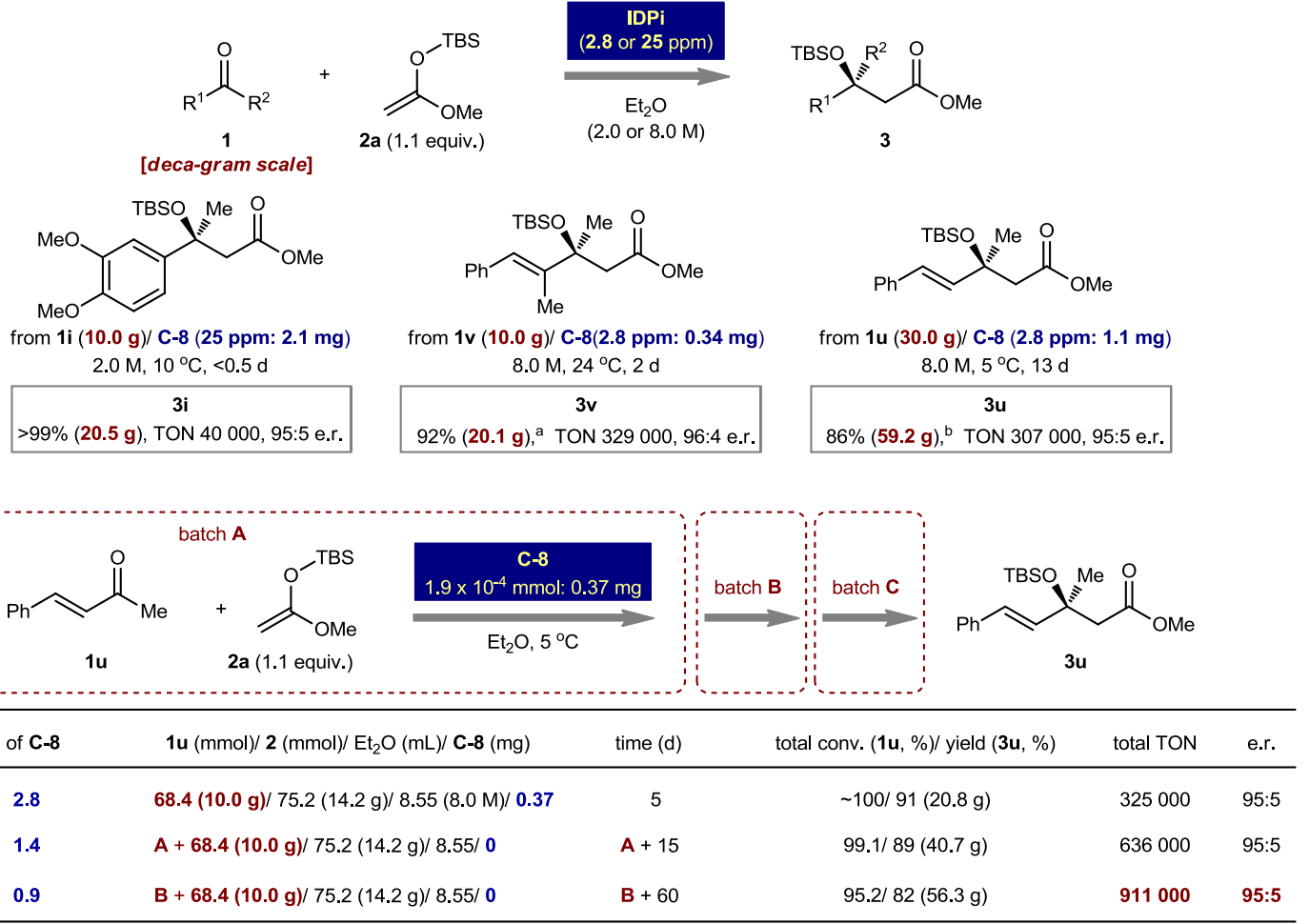

d

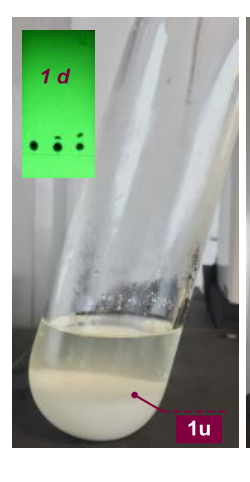

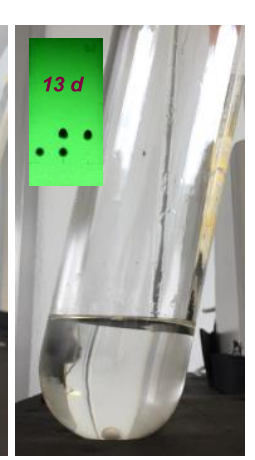

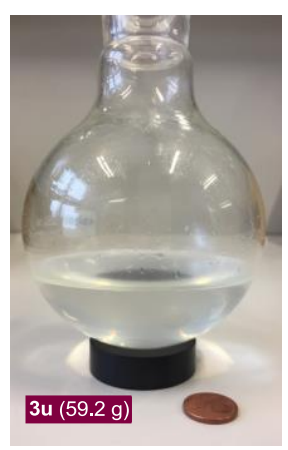

e using DSI C-1 $(0.1 \mathrm{~mol} \%=1,000 \mathrm{ppm}) / \mathbf{1} \mathbf{u}(6.84 \mathrm{mmol}) / \mathbf{2 a}(1.1$ equiv. $) / \mathrm{Et}_{2} \mathrm{O}(8.0 \mathrm{M}) / 5^{\circ} \mathrm{C}, 24 \mathrm{~h}$ :

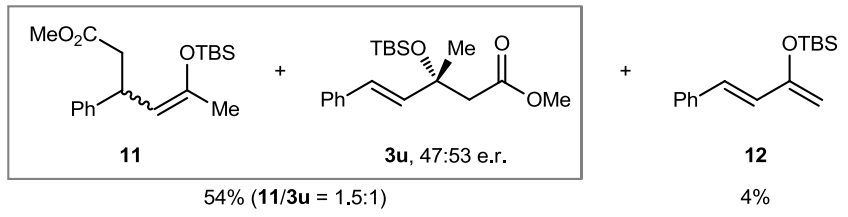

Figure 3 | Mukaiyama aldol reaction of ketones on a preparative scale with catalyst loadings between 0.9 to 25 ppm. a, Reaction details and results. $\mathbf{b}$, Repeated addition of starting materials. $\mathbf{c}$, Reaction progress of the aldol reaction of $\mathbf{1} \mathbf{u}$ to $3 \mathbf{u}$ catalyzed by $\mathbf{C}-\mathbf{8}(0.9$ to $2.8 \mathrm{ppm})$. d, Pictures of crude reaction mixtures with TLC analyses (left picture and center picture: after $1 \mathrm{~d}$ and $13 \mathrm{~d}$; TLC eluent: acetone/ $n$-hexanes $=1: 20$, left lane: $1 \mathbf{u}$ / center lane: co-spot/ right lane: mixture) and dried product $3 \mathbf{u}$ (right picture, $250 \mathrm{~mL}$ round-bottom flask). e, The reaction outcome using DSI C-1 $(0.1 \mathrm{~mol} \%)$ as a catalyst. ${ }^{\text {a }}$ No 1,4 -adduct was observed. ${ }^{\mathrm{b}}$ The corrected yield of 1,2 -adduct is indicated. $\mathrm{TON}=$ turnover number. 


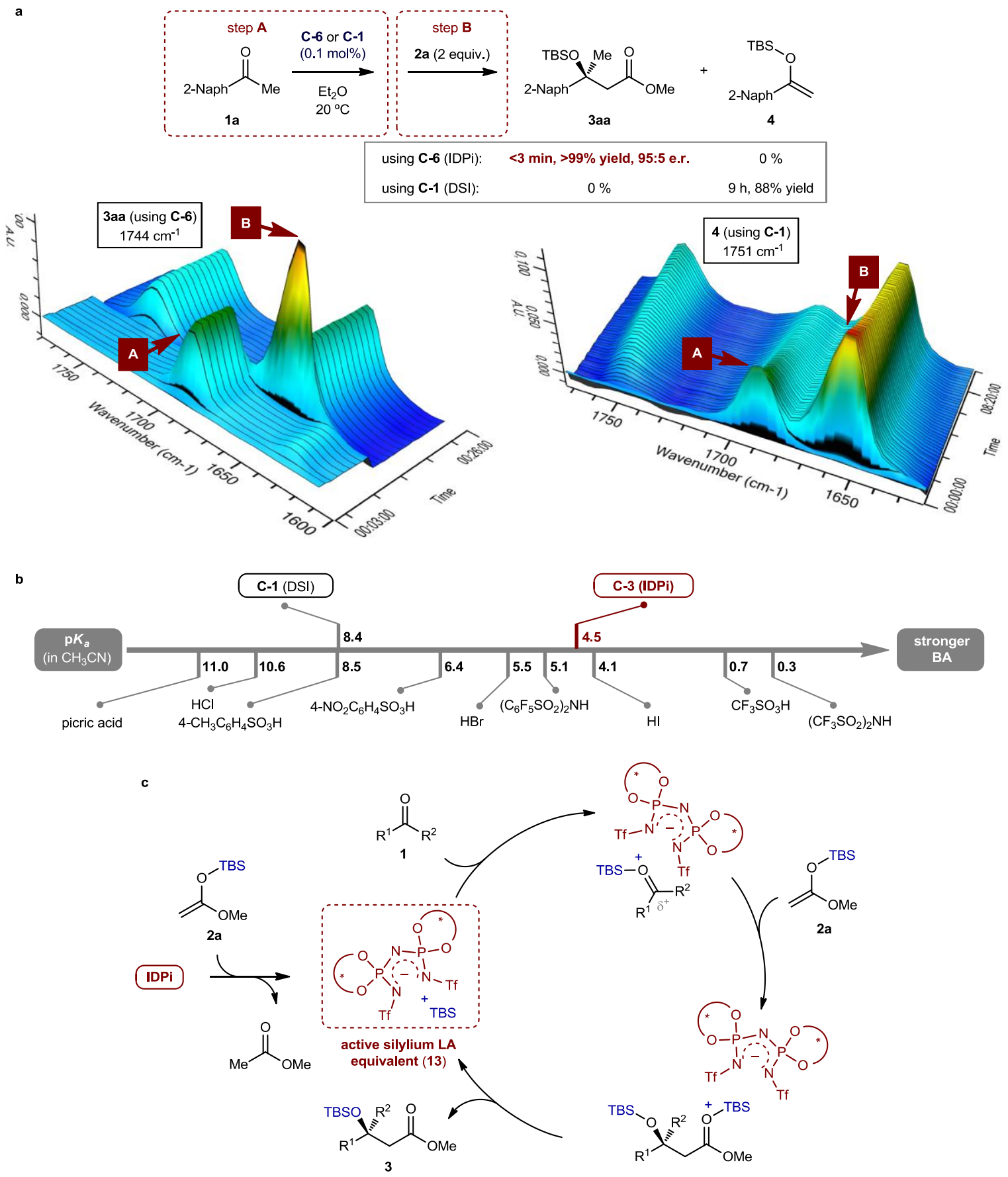

Figure 4 | Study on the reaction mechanism. a, Analytical results of the in situ FT-IR investigation on the catalytic Mukaiyama aldol reaction of ketone 1a with silyl ketene acetal 2a using IDPi C-6 (left picture) and DSI C-1 (right picture) as catalysts. b, The measured pKa values of chiral acids (DSI C- 1 and IDPi C-3) and reported pKa values of achiral acids in acetonitrile (see Supplementary Section 9 for details). BA = Brønsted acid, LA = Lewis acid. c, Proposed reaction mechanism of the IDPi catalyzed Mukaiyama aldol reaction. 


\section{Conclusions}

In conclusion, we have developed a broadly applicable Mukaiyama aldol reaction of ketones $\mathbf{1}$ with silyl ketene acetals 2 . In the presence of IDPi catalysts, a variety of (hetero)aryl-alkyl and alkyl-alkyl ketones are converted into the corresponding tertiary aldols in almost quantitative yields (up to 99\% yield) and with very high to excellent enantioselectivities (e.r. up to 99:1). The developed method is operationally simple, scalable, and the obtained products can be readily derivatized. We also show that only extremely low catalyst loadings are generally required, with 50-500 ppm being sufficient to obtain the desired products quantitatively in typically less than $12 \mathrm{~h}$. We also report preparative scale reactions that require only single digit ppm loadings and in one case, even less than 1 ppm. While the reactions under these extreme conditions require purified reagents and extended reaction times (2-80 days), to our knowledge, the catalyst loadings reported are unprecedented in asymmetric carbon-carbon bond forming reactions.

\section{Method}

General procedure for the $\mathbf{3 0}$ gram scale catalytic Mukaiyama aldol reaction of ketones. Ketone $\mathbf{1 u}$ (30.0 g, $205 \mathrm{mmol}, 1$ equiv.) was placed in a flame-dried J. Young Schlenk flask, equipped with a teflon-coated magnetic stirring bar. IDPi C-8 (1.1 mg, $5.7 \times 10^{-4}$ mmol, $2.8 \mathrm{ppm})$ and $\mathrm{Et}_{2} \mathrm{O}(8.0 \mathrm{M}, 25.6 \mathrm{~mL})$ were added at $25^{\circ} \mathrm{C}$ and stirred for $30 \mathrm{~min}$. The reaction mixture was cooled to $-78{ }^{\circ} \mathrm{C}$ and silyl ketene acetal $2 \mathrm{a}\left(42.5 \mathrm{~g}, 226 \mathrm{mmol}, 1.1\right.$ equiv.) was slowly added. The reaction mixture was stirred for $60 \mathrm{~min}$ at $-10{ }^{\circ} \mathrm{C}$, then for $60 \mathrm{~min}$ at $0^{\circ} \mathrm{C}$, and finally stirred for 13 days at $5^{\circ} \mathrm{C}$. Organic volatiles (boiling points of volatiles: $\mathrm{Et}_{2} \mathrm{O}=34.6{ }^{\circ} \mathrm{C}$; silyl ketene acetal $2 \mathrm{a}$ $=62{ }^{\circ} \mathrm{C} / 12 \mathrm{mbar}$ ) were evaporated in vacuo to afford the desired tertiary aldol product $3 \mathrm{u}(59.2 \mathrm{~g}, 86 \%$ yield, $95: 5 \mathrm{e} . \mathrm{r}$. $)$.

Full experimental details and the characterization of new compounds are available in the Supplementary Information.

\section{Data availability}

The data that support the findings of this study are available from the corresponding author upon request.

\section{Competing Interests}

The authors declare no competing financial and non-financial interest.

\section{References}

1. List, B. et al. A Catalytic enantioselective route to hydroxy-substituted quaternary carbon centers: Resolution of tertiary aldols with a catalytic antibody. J. Am. Chem. Soc. 121, 7283-7291 (1999).

2. Nelson, S. G. Catalyzed enantioselective aldol additions of latent enolate equivalents. Tetrahedron: Asymmetry 9, 357-389 (1998).

3. Mahrwald, R. Diastereoselection in Lewis-acid-mediated aldol additions. Chem. Rev. 99, 1095-1120 (1999).

4. Machajewski, T. D. \& Wong, C.-H. The catalytic asymmetric aldol reaction. Angew. Chem. Int. Ed. 39, 1352-1375 (2000).

5. Mahrwald, R. Modern aldol reactions (Wiley-VCH Verlag GmbH \& Co., 2004).

6. Mahrwald, R. Modern methods in stereoselective aldol reactions (Wiley-VCH Verlag GmbH \& Co., 2013).

7. Cozzi, P. G., Hilgraf, R. \& Zimmermann, N. Enantioselective catalytic formation of quaternary stereogenic centers. Eur. J. Org. Chem. 5969-5994 (2007).

8. Hatano, M. \& Ishihara, K. Recent progress in the catalytic synthesis of tertiary alcohols from ketones with organometallic reagents. Synthesis 16471675 (2008).

9. Adachi, S. \& Harada, T. Catalytic enantioselective aldol additions to ketones. Eur. J. Org. Chem. 3661-3671 (2009).

10. Elliott, M. L., Urban, F. J. \& Bordner, J. Synthesis and absolute configuration of $(R)$ - and (S)-ethyl 3-(4-oxocyclohex-2-enyl)propionate. J. Org. Chem. 50, 1752-1755 (1985).

11. Rodriguez, M. J. Process for performing retro-aldol reactions. US Patent 5,677,423 filed 10 Dec 1996.

12. Matovic, R., Ivkovic, A., Manojlovic, M., Tokic-Vujosevic, Z. \& Saicic, R. N. Ring closing metathesis/fragmentation route to (Z)-configured medium ring cycloalkenes. Total synthesis of ( \pm )-Periplanone C. J. Org. Chem. 71, 9411-9419 (2006).

13. Hatano, M., Takagi, E. \& Ishihara, K. Sodium phenoxide-phosphine oxides as extremely active Lewis base catalysts for the Mukaiyama aldol reaction with ketones. Org. Lett. 9, 4527-4530 (2007).

14. Kobayashi, S., Fujishita, Y. \& Mukaiyama, T. The efficient catalytic asymmetric aldol-type reaction. Chem. Lett. 19, 1455-1458 (1990). 
15. Kan, S. B. J., Ng, K. K. H. \& Paterson, I. The impact of the Mukaiyama aldol reaction in total synthesis. Angew. Chem. Int. Ed. 52, 9097-9108 (2013).

16. Matsuo, J.-i. \& Murakami, M. The Mukaiyama adol reaction: 40 Years of continuous development. Angew. Chem. Int. Ed. 52, 9109-9118 (2013).

17. Denmark, S. E. \& Fan, Y. Catalytic, enantioselective aldol additions to ketones. J. Am. Chem. Soc. 124, 4233-4235 (2002).

18. Denmark, S. E., Fan, Y. \& Eastgate, M. D. Lewis base catalyzed, enantioselective aldol addition of methyl trichlorosilyl ketene acetal to ketones. J. Org. Chem. 70, 5235-5248 (2005).

19. Oisaki, K., Zhao, D., Kanai, M. \& Shibasaki, M. Catalytic enantioselective aldol reaction to ketones. J. Am. Chem. Soc. 128, 7164-7165 (2006).

20. Moreau, X., Bazán-Tejeda, B. \& Campagne, J.-M. Catalytic and asymmetric vinylogous Mukaiyama reactions on aliphatic ketones: Formal asymmetric synthesis of Taurospongin A. J. Am. Chem. Soc. 127, 7288-7289 (2005).

21. Kaib, P. S. J., Schreyer, L., Lee, S., Properzi, R. \& List, B. Extremely active organocatalysts enable a highly enantioselective addition of allyltrimethylsilane to aldehydes. Angew. Chem. Int. Ed. 55, 13200-13203 (2016).

22. Xie, Y. et al. Catalytic asymmetric vinylogous Prins cyclization: A highly diastereo- and enantioselective entry to tetrahydrofurans. J. Am. Chem. Soc. 138, 14538-14541 (2016).

23. Lee, S., Kaib, P. S. J. \& List, B. Asymmetric catalysis via cyclic, aliphatic oxocarbenium ions. J. Am. Chem. Soc., 139, 2156-2159 (2017).

24. Liu, L. et al. Catalytic Asymmetric [4+2]-cycloaddition of dienes with aldehydes. J. Am. Chem. Soc., 139, 13656-13659 (2017).

25. Gatzenmeier, T., Kaib, P. S. J., Lingnau, J. B., Goddard, R. \& List, B. The catalytic asymmetric Mukaiyama-Michael reaction of silyl ketene acetals with $\alpha, \beta$-unsaturated methyl esters. Angew. Chem. Int. Ed. 57, 2464-2468 (2018).

26. Mahlau, M. \& List, B. Asymmetric counteranion-directed catalysis: Concept, definition, and applications. Angew. Chem. Int. Ed. 52, 518-533 (2013).

27. García-García, P., Lay, F., García-García, P., Rabalakos, C. \& List, B. A powerful chiral counteranion motif for asymmetric catalysis. Angew. Chem. Int. Ed. 48, 4363-4366 (2009).

28. Ratjen, L., Garcia-Garcia, P., Lay, F., Beck, M. E. \& List, B. Disulfonimide-catalyzed asymmetric vinylogous and bisvinylogous Mukaiyama aldol reactions. Angew. Chem. Int. Ed. 50, 754-758 (2011).

29. Tap, A., Blond, A., Wakchaure, V. N. \& List, B. Chiral allenes via alkynylogous Mukaiyama aldol reaction. Angew. Chem. Int. Ed. 55, $8962-8965$ (2016).

30. van Gemmeren, M., Lay , F. \& List, B. Asymmetric catalysis using chiral, enantiopure disulfonimides. Aldrichimica Acta 47, 3-13 (2014).

31. James, T., van Gemmeren, M. \& List, B. Development and applications of disulfonimides in enantioselective organocatalysis. Chem. Rev. 115, 9388-9409 (2015).

32. Giacalone, F., Gruttadauria, M., Agrigento, P. \& Noto, R. Low-loading asymmetric organocatalysis. Chem. Soc. Rev. 41, 2406-2447 (2012).

33. Park, S. Y. et al. Parts-per-million level loading organocatalysed enantioselective silylation of alcohols. Nat. Commun. 6:7512 doi: 10.1038/ncomms8512 (2015).

34. Xu, W. et al. Metal-templated design: Enantioselective hydrogen-bond-driven catalysis requiring only parts-per-million catalyst loading. J. Am. Chem. Soc. 138, 8774-8780 (2016).

35. Zhang, Z. \& List, B. Kinetics of the chiral disulfonimide-catalyzed Mukaiyama aldol reaction. Asian J. Org. Chem. 2, 957-960 (2013).

36. Zhang Z. et al. Asymmetric counteranion-directed Lewis acid organocatalysis for the scalable cyanosilylation of aldehydes. Nat. Commun.7:12478 doi: $10.1038 /$ ncomms12478 (2016).

37. Song, J. J. et al. N-Heterocyclic carbene-catalyzed silyl enol ether formation. Org. Lett. 10, 877-880 (2008)

\section{Acknowledgements}

Generous support from the Max Planck Society, the Deutsche Forschungsgemeinschaft (Leibniz Award to B.L. and Cluster of Excellence RESOLV, EXC 1069), and the European Research Council (Advanced Grant "C-H Acids for Organic Synthesis, CHAOS") are gratefully acknowledged. We thank Jennifer L. Kennemur for her suggestions during the preparation of this manuscript, the technicians of our group, and the members of our NMR, MS and HPLC departments for their excellent service. The work of K.K. and I.L. was supported by the grant IUT20-14 from the Estonian Ministry of Education and Research. Dedicated to Professor Teruaki Mukaiyama in celebration of his 90th birthday (Sotsuju). 


\section{Author contributions}

H.Y.B. developed the reaction and investigated the substrate scope, derivatizations of the aldol products, and implemented in situ FTIR study. D.H. first observed the high activity of IDPi catalysts in the described reaction. The IDPi catalysts were developed by H.Y.B., P.S.J.K. and B.L.. H.Y.B., P.S.J.K., P.K. and S.L. synthesized the IDPi catalysts used in this study. H.Y.B., C.K.D. and A.D. investigated large-scale and low-catalyst loading experiments. K.K. and I.L. measured $\mathrm{p} K_{\mathrm{a}}$ values of acid catalysts. B.L. designed and oversaw the project. H.Y.B. and B.L. wrote the manuscript.

\section{Additional information}

Supplementary information and chemical compound information are available in the online version of the publication. Reprints and permissions information is available online at www.nature.com/reprints. Correspondence and requests for materials should be addressed to B.L.

\section{Competing financial interests}

The authors declare no competing financial interests. 